
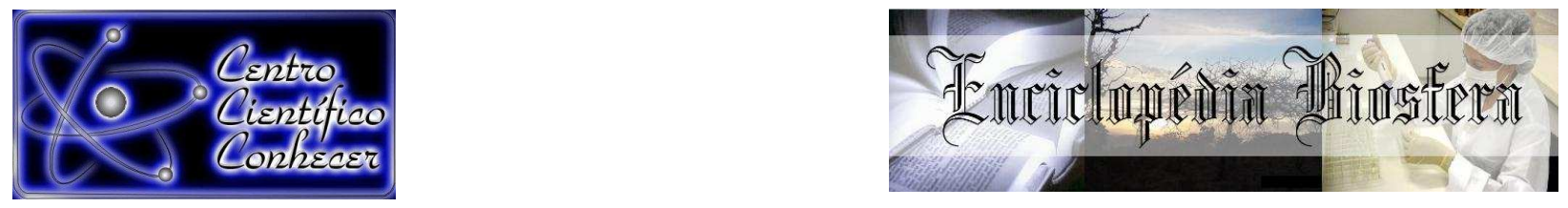

\title{
EFEITO DA ADUBAÇÃO VERDE NA ESTABILIDADE DE AGREGADOS DE UM SOLO SOB CULTIVO DE HORTALIÇAS ORGÂNICAS NA REGIÃO DE CAPIM BRANCO - MG
}

Aline Martineli Batista ${ }^{1}$, Vívian Ribeiro de Oliveira Preto ${ }^{2}$, Matheus Pena Campos ${ }^{3}$, Bruno Montoani Silva ${ }^{4}$, Samuel Petraccone Caixeta ${ }^{5}$

1 Graduanda de Engenharia Agronômica da Universidade Federal de São João Del-Rei / Bolsista do PET Agronomia (martineli.aline@gmail.com) Minas Gerais Brasil

2 Graduanda de Engenharia Agronômica da Universidade Federal de São João

Del-Rei / Bolsista ITI-A do CNPq - CVT Guayi

3 Mestrando de Ciências Agrárias da Universidade Federal de São João Del-Rei / Bolsista da CAPES

4 Professor Doutor do Departamento de Ciências Agrárias da Universidade Federal de São João Del-Rei

5 Professor Doutor do Departamento de Ciências Agrárias da Universidade Federal de São João Del-Rei

Recebido em: 08/09/2015 - Aprovado em: 14/11/2015 - Publicado em: 01/12/2015 DOI: http://dx.doi.org/10.18677/Enciclopedia_Biosfera_2015_141

\section{RESUMO}

O uso do adubo verde fornece ao solo matéria orgânica que melhora as suas condições físico-químicas. Objetivou-se avaliar a estabilidade de agregados em áreas de cultivo orgânico sob diferentes épocas de uso de adubação verde, no município de Capim Branco - MG, a fim de investigar se há melhorias na qualidade física do solo. Foram estudados os tratamentos: cultivo de adubo verde recémroçado (T1); cultivo de hortaliças orgânicas em solo no qual havia sido cultivado adubo verde há um ano (T2); cultivo de hortaliças orgânicas em solo no qual havia sido cultivado adubo verde há três anos (T3); e cultivo de hortaliças orgânicas em solo no qual nunca havia sido cultivado adubo verde (T4). Amostrou-se o solo nas camadas de 0-10 e 10-20 cm em cinco repetições. Foi realizada a análise da estabilidade de agregados, sendo determinados o diâmetro médio ponderado (DMP) e o diâmetro médio geométrico (DMG). Determinou-se também o índice de floculação (IF), por meio da avaliação da argila dispersa em água (ADA) e caracterização granulométrica. $O$ delineamento estatístico utilizado foi o inteiramente casualizado. Os dados foram submetidos à análise de variância e as médias foram comparadas utilizando-se o teste Scott-Knott a $5 \%$ de probabilidade. Não houve diferença significativa $(p<0,05)$ para as classes de diâmetro de agregados, nem para DMG e DMP. O uso do adubo verde pelos produtores de Capim Branco - MG não tem promovido alterações estruturais no solo, uma vez que o uso da prática não tem sido contínuo ao longo dos ciclos de cultivo.

PALAVRAS-CHAVE: estrutura do solo, qualidade física do solo, sistema orgânico, Crotalaria juncea L 


\title{
THE EFFECT OF GREEN MANURE ON THE STABILITY OF SOIL AGGREGATES AT ORGANIC VEGETABLES GROWING AREAS IN CAPIM BRANCO/MG
}

\begin{abstract}
The use of green manure provides organic matter to the soil, which improves its physical conditions due to the fact that it is the main cementing agent that forms the soil aggregates. This study aimed to evaluate the stability of soil aggregates in areas of organic farming at different times of use of green manure, in Capim Branco/MG, in order to investigate if there is a soil improvement regarding its physical quality. Four treatments were studied: newly scuffed green manure (T1); cultivation of organic vegetables in which had been cultivated green manure a year ago in the area (T2); cultivation of organic vegetables in which had been cultivated green manure for three years in the area (T3); and cultivation of organic vegetables in which had never been grown green manure before (T4). The samples were collected at $0-10$ and $10-20 \mathrm{~cm}$ in five replicates. The analysis of aggregate stability was performed, to determine the mean weight diameter (MWD) and the geometric mean diameter (GMD). This study also determined the flocculation ind ex (IF), through the evaluation of water dispersible clay (WDC) and soil particle size characterization. The statistical design was completely randomized. Data were subjected to analysis of variance, and means were compared using the Scott- Knott test at $5 \%$ of probability. There were no significant differences $(p<0,05)$ for aggregate diameter classes, nor MWD and GMD. The use of the green manure by producers in Capim Branco/MG, does not promote structural changes in the soil, since the use of this practice is not continuous throughout the crop cycle.
\end{abstract}

KEYWORDS: soil physical quality, organic production system, soil structure, Crotalaria juncea L.

\section{INTRODUÇÃO}

O cultivo do solo modifica suas propriedades físicas, químicas e biológicas e o tipo de manejo adotado pode fazer com que as alterações observadas sejam mais ou menos evidentes, sendo estas mais evidentes em sistemas convencionais do que em sistemas conservacionistas (BERTOL et al., 2004). Isto ocorre porque os sistemas conservacionistas visam prevenir o ambiente contra a degradação física do solo causada por compactação, e, principalmente, pela erosão (OLIVEIRA et al., 2015).

A estrutura do solo diz respeito ao arranjo das partículas e do espaço poroso constituindo um ambiente dinâmico, que define o comportamento dos processos que ocorrem no solo (FERREIRA, 2010), e a alteração deste arranjo pode resultar em alteração na qualidade do solo. Segundo STEFANOSKI et al. (2013), a avaliação da qualidade física do solo, ou seja, da qualidade estrutural, é inferida por meio de indicadores que consistem em atributos físicos do solo. Dentre os diversos indicadores existentes, a estabilidade de agregados está entre os atributos do solo mais utilizados para esta finalidade (SINGER \& EWING, 2000).

Uma das maneiras de melhorar a qualidade estrutural de um solo, segundo BETIOLI JÚNIOR et al. (2012), é através da conservação e adição de compostos orgânicos no solo, o que, de acordo com OLIVEIRA et al. (2015), traz, além de benefícios químicos, melhorias na qualidade física do solo. A incorporação da 
matéria orgânica ao solo, de acordo com MIRANDA et al. (2011), pode promover maior agregação das partículas do solo, pois segundo VASCONCELOS et al. (2014), ela é o principal agente cimentante que forma os agregados.

Segundo BUZINARO et al. (2009), o uso da adubação verde, como prática conservacionista, promove ao solo aumento de matéria orgânica e nutrientes que são aproveitados pelas plantas, o que acarreta na redução quantitativa da necessidade de adubos químicos. Além disso, a condição primordial para garantir alta produtividade é possuir um solo com bom estado de agregação (HICKMANN et al., 2011). Por esta razão, na produção orgânica, esta é uma estratégia importante que possibilita maior produtividade e melhor conservação do solo (SILVA et al., 2011).

No entanto o uso da adubação verde deve ser manejado de forma correta, em rotação, sucessão ou consorciação com as culturas de interesse comercial para que sejam obtidos os resultados esperados (CALEGARI et al., 1993). PERIN et al. (2002) observaram que o solo sob cobertura de leguminosas herbáceas perenes apresenta maiores índices de agregação do que áreas não cobertas. CUNHA et al. (2011) notaram também que ocorreram diferenças na agregação do solo ao estudar os atributos físicos do solo em diferentes sistemas de preparo e culturas de cobertura na produção orgânica de feijão e milho. Porém, o número de cultivos para alcançar benefícios é variável e carece de informações na literatura.

Produtores do município de Capim Branco - MG vem associando a produção satisfatória de hortaliças orgânicas à utilização da adubação verde, mas seus relatos mostram dúvida quanto à eficiência da prática. Segundo TUBALDINI \& COELHO (2002), a Prefeitura Municipal e a EMATER visam tornar este município um polo de horticultura orgânica devido ao extenso número de produtores da região que utilizam este sistema de manejo.

Nesse contexto, objetivou-se com o presente trabalho, avaliar a estabilidade de agregados em áreas de cultivo orgânico sob diferentes tempos de uso da adubação verde, conforme adotado pelos produtores do município de Capim Branco - MG, a fim de investigar se realmente ocorrem melhorias na qualidade física do solo promovidas por este manejo conservacionista.

\section{MATERIAL E MÉTODOS}

O presente trabalho foi realizado na região metropolitana de Belo Horizonte, no município de Capim Branco - MG, que faz parte do cinturão verde e está localizado sob a latitude -1932'51"S, longitude -4 407'51'W, altitude média de 853 m (MAPCOORDINATES, 2015).

As amostras de solo foram coletadas em glebas comerciais de produção de hortaliças orgânicas vizinhas de uma propriedade do município de Capim Branco MG, em março de 2015 nas camadas de 0-10 e 10-20 cm, em cinco repetições. O produtor tem utilizado a prática da adubação verde por um ciclo, substituindo-as posteriormente por hortaliças, mas este, não segue um calendário planejado por ano agrícola para o uso dessa prática conservacionista.

As áreas avaliadas compuseram os quatro tratamentos, sendo elas: cultivo de adubo verde recém-roçado (T1); cultivo de hortaliças orgânicas em solo no qual havia sido cultivado adubo verde há um ano (T2); cultivo de hortaliças orgânicas em solo no qual havia sido cultivado adubo verde há três anos (T3); e cultivo de hortaliças orgânicas em solo no qual nunca havia sido cultivado adubo verde (T4). 
Estas áreas representavam o manejo do adubo verde adotado na produção de hortaliças dessa propriedade que é representativa da região. $O$ adubo verde utilizado nas áreas foi a crotalária (Crotalaria juncea L.), que é apontada como uma das espécies de plantas de cobertura com melhor potencial para reestruturação dos atributos químicos e físicos do solo (CARDOSO et al., 2013).

A estabilidade de agregados foi realizada pela metodologia do tamisamento úmido (EMBRAPA, 2011). As amostras de solo foram secas ao ar e posteriormente destorroadas e peneiradas em peneiras de malha de 8 e $4 \mathrm{~mm}$. Foram pesados $25 \mathrm{~g}$ dos agregados entre $8 \mathrm{~mm}$ e $4 \mathrm{~mm}$, e estes foram pré-umedecidos por ascensão capilar durante uma hora. Decorrido este tempo, a amostra de solo foi colocada em agitação por 15 minutos em um Agitador de Yoder utilizando um conjunto de peneiras com abertura de malhas de 2,00; 1,00; 0,50; 0,25 e 0,09 mm. Em seguida as amostras retidas em cada peneira foram colocadas em recipientes previamente tarados e identificados e levadas à estufa de secagem por 24 horas à $105^{\circ} \mathrm{C}$. Após este tempo, o solo contido em cada recipiente foi pesado e determinou-se a percentagem de agregados de diferentes tamanhos, sendo: de 8,00 a 2,00; de 2,00 a 1,00; de 1,00 a 0,50; de 0,50 a 0,25; de 0,25 a 0,09 e < 0,09 mm. A partir destes dados foram determinados, segundo CASTRO FILHO et al. (1998), o diâmetro médio geométrico (DMG) e o diâmetro médio ponderado (DMP) dos agregados.

As mesmas amostras foram passadas em peneiras com aberturas de $2 \mathrm{~mm}$ e fez-se a análise granulométrica e a argila dispersa em água (ADA) conforme a metodologia apresentada em EMBRAPA (2011). A análise granulométrica foi realizada pelo método da pipeta, utilizando agitação lenta por 16 horas e $\mathrm{NaOH}$ como dispersante químico. Foi feita a correção para a umidade inicial da amostra, sendo considerado nos cálculos a terra fina seca em estufa (TFSE). Já a ADA foi obtida pelo mesmo procedimento, sem adição de $\mathrm{NaOH}$. Com os valores obtidos na análise granulométrica e na ADA calculou-se o índice de floculação (IF), conforme EMBRAPA (2011).

O delineamento estatístico utilizado foi o inteiramente casualizado (DIC). Os dados foram submetidos à análise de variância (ANOVA) e as médias foram comparadas utilizando-se o teste Scott-Knott a 5\% de probabilidade.

\section{RESULTADOS E DISCUSSÃO}

Dentre as classes de diâmetro de agregados avaliadas não foi observada diferença significativa $(p<0,05)$ entre os tratamentos em nenhuma das profundidades $(0-10$ e $10-20 \mathrm{~cm})$, como pode ser verificado pelas figuras 1 e 2 . 


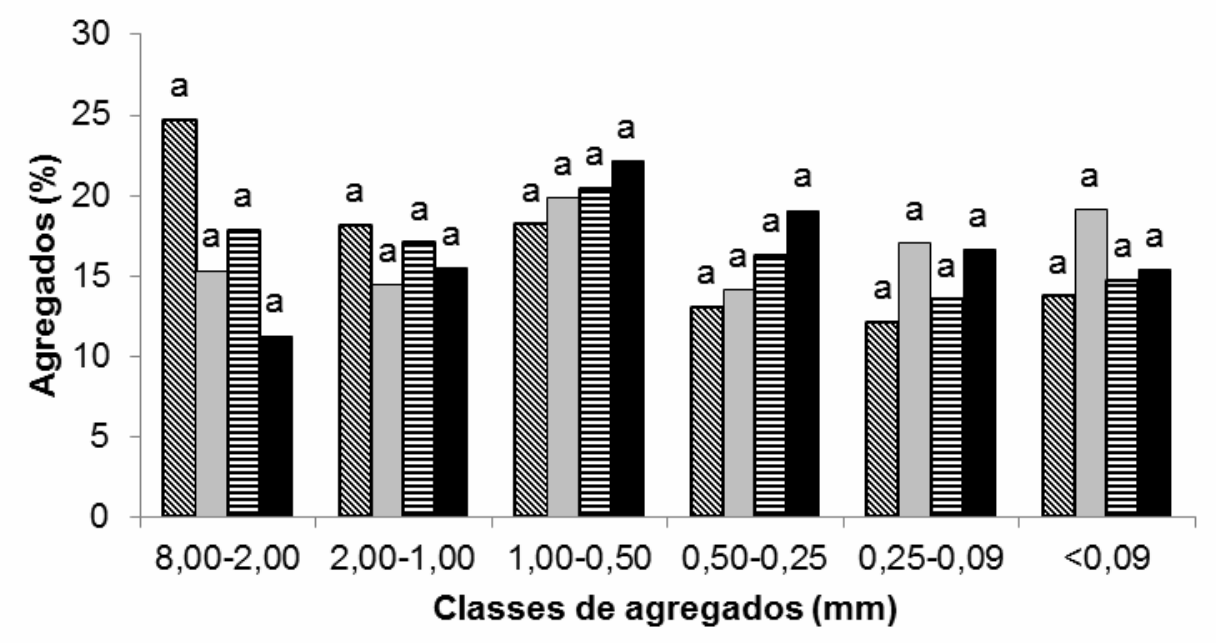

FIGURA 1 Percentagem média de agregados por classes de agregados para os tratamentos (T1: adubo verde recém roçado, T2: adubo verde há 1 ano, T3: adubo verde há 3 anos e T4: sem adubo verde) na profundidade de $0-10 \mathrm{~cm}$. Médias com letras iguais comparando os tratamentos para cada classe de agregados não diferem entre si pelo teste de ScottKnott à $5 \%$ de probabilidade.

$\mathbb{\nabla T} 1 \square \mathrm{T} 2$ घT3 $\square \mathrm{T} 4$

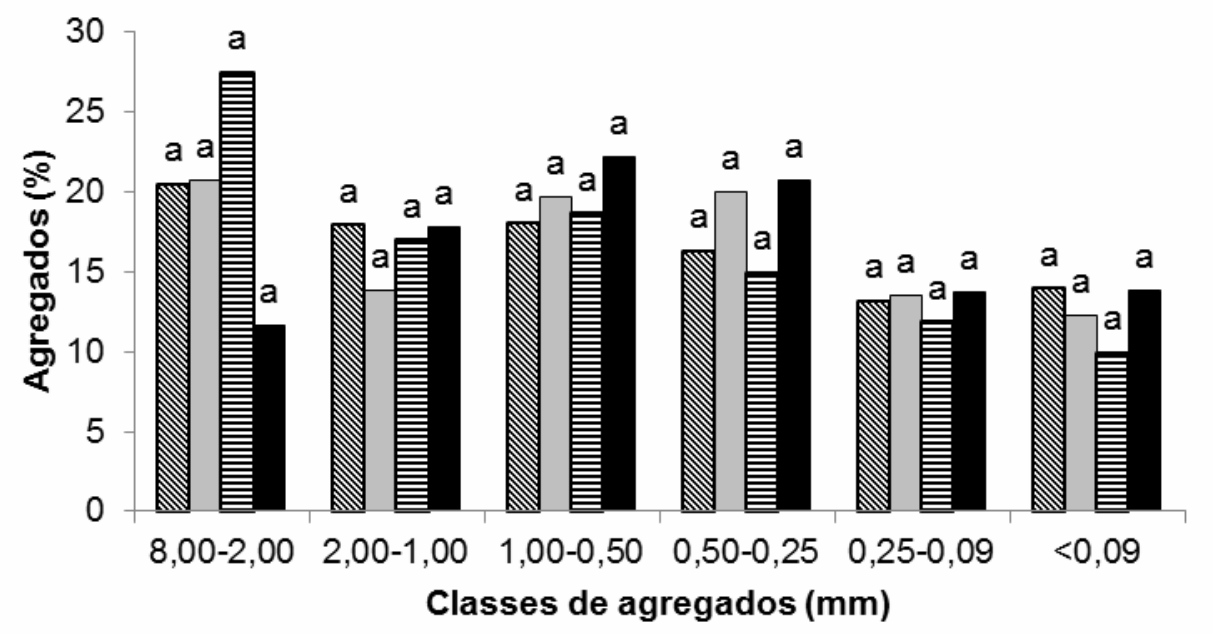

FIGURA 2 Percentagem média de agregados por classes de agregados para os tratamentos (T1: adubo verde recém roçado, T2: adubo verde há 1 ano, T3: adubo verde há 3 anos e T4: sem adubo verde) na profundidade de $10-20 \mathrm{~cm}$. Médias com letras iguais comparando os tratamentos para cada classe de agregados não diferem entre si pelo teste de ScottKnott à $5 \%$ de probabilidade. 
Estes dados corroboram com CARVALHO et al. (2014) que também observaram menor diferenciação entre as classes de agregados ao comparar a vegetação de cerrado e milho cultivado durante 30 anos. Sabe-se que quanto maior for a percentagem de agregados retidos nas peneiras com malhas maiores, maior será o DMP e que o DMG representa uma estimativa da classe de agregados de maior ocorrência (HICKMANN et al., 2011). Assim, em razão da não diferenciação significativa entre as classes de agregados avaliadas, estes também não diferiram estatisticamente (Figura 3).

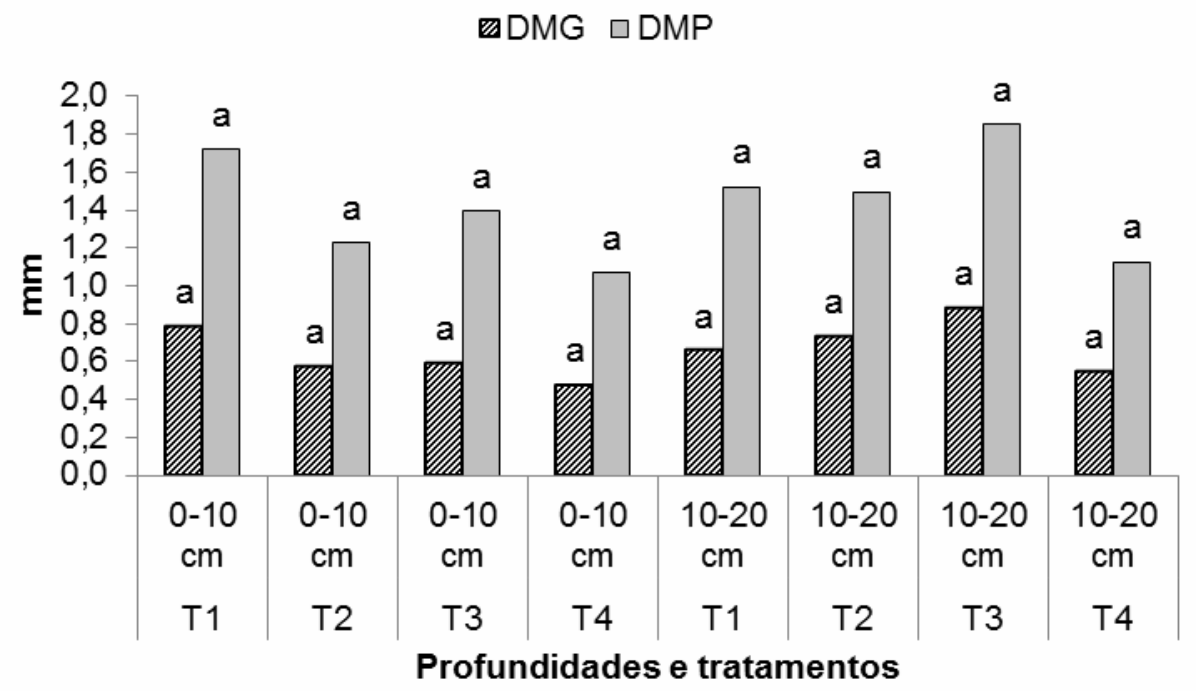

FIGURA 3 DMG e DMP médios dos tratamentos (T1: adubo verde recém roçado, T2: adubo verde há 1 ano, T3: adubo verde há 3 anos e T4: sem adubo verde) nas profundidades de 0-10 e 10-20 $\mathrm{cm}$. Médias seguidas por letras iguais comparando os tratamentos para DMG e DMP não diferem entre si pelo teste de Scott-Knott à $5 \%$ de probabilidade.

Estes dados demonstram que o uso do adubo verde não tem promovido alterações na qualidade estrutural do solo de acordo com o manejo adotado pelos produtores. Isso pode ser explicado pela forma como esta prática é empregada, apenas em um ano agrícola, de forma descontínua, e não como sucessão ou rotação de culturas com calendário agrícola planejado. No entanto, HICKMANN \& COSTA (2012) demonstraram em seu trabalho que para todos os sistemas de manejo avaliados, inclusive um que envolvia o uso correto de adubação verde, a distribuição dos agregados estáveis em água indicou predominância de macro agregados (classe 4,0-2,0 mm) para todas as camadas de solo avaliadas.

Por outro lado, destaca-se que o uso adequado dos adubos verdes é uma alternativa para a adubação complementar de hortaliças, como observado por FONTANÉTTI et al. (2006), que obteve ainda no primeiro ano de cultivo orgânico, alfaces americanas e repolhos com pesos satisfatórios para o mercado.

Todavia, segundo ALCÂNTARA et al. (2000), os efeitos promovidos pela utilização da adubação verde variam de acordo com a espécie utilizada, a época de plantio, a época do corte do adubo verde e as condições locais. $E$, de acordo com 
ANDRADE et al. (2009), do ponto de vista da física do solo, tem sido estimulado o uso da rotação de culturas para manter e/ou aumentar os teores de matéria orgânica, criar poros biológicos, melhorar a estrutura e manter palha suficiente na superfície do solo. Assim, se não utilizado em rotação, ou mesmo consórcio com a cultura principal, os benefícios promovidos por esta prática conservacionista podem não ser observados.

Para a análise granulométrica verificou-se que, para os teores de areia, silte e argila, apenas a areia em ambas as profundidades apresentou significância $(p<0,05)$, como mostrado na figura 4 e 5 . Possivelmente este resultado deve-se à uma pequena variação pedológica. Verifica-se que não houve diferenças entre os tratamentos para a ADA e o IF nas profundidades avaliadas (figura 4 e 5), o que sugere ausência de alterações no estado de agregação do solo como função dos tratamentos, confirmando os resultados observados para estabilidade de agregados.

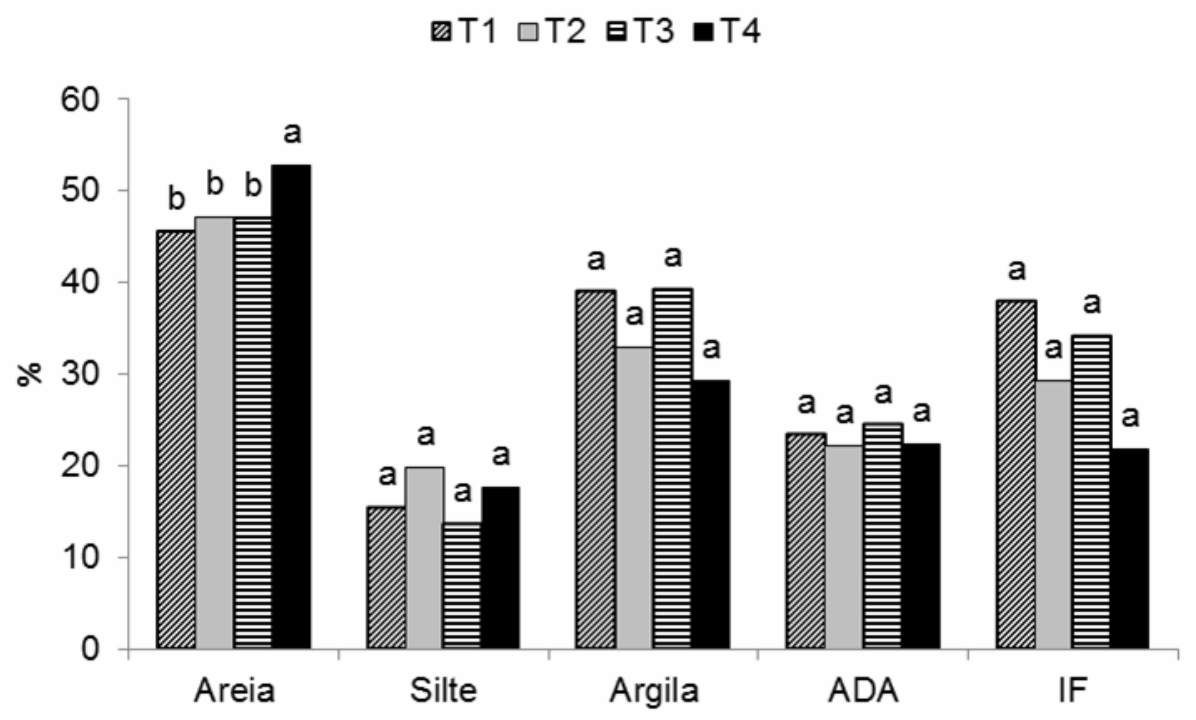

FIGURA 4 Atributos avaliados (areia, silte, argila, ADA e IF) na camada de 0-10 $\mathrm{cm}$, para os tratamentos (T1: adubo verde recém roçado, $\mathrm{T} 2$ : adubo verde há 1 ano, T3: adubo verde há 3 anos e T4: sem adubo verde). Médias iguais comparando os tratamentos para cada atributo avaliado não diferem entre si pelo teste de Scott-Knott à 5\% de probabilidade. 


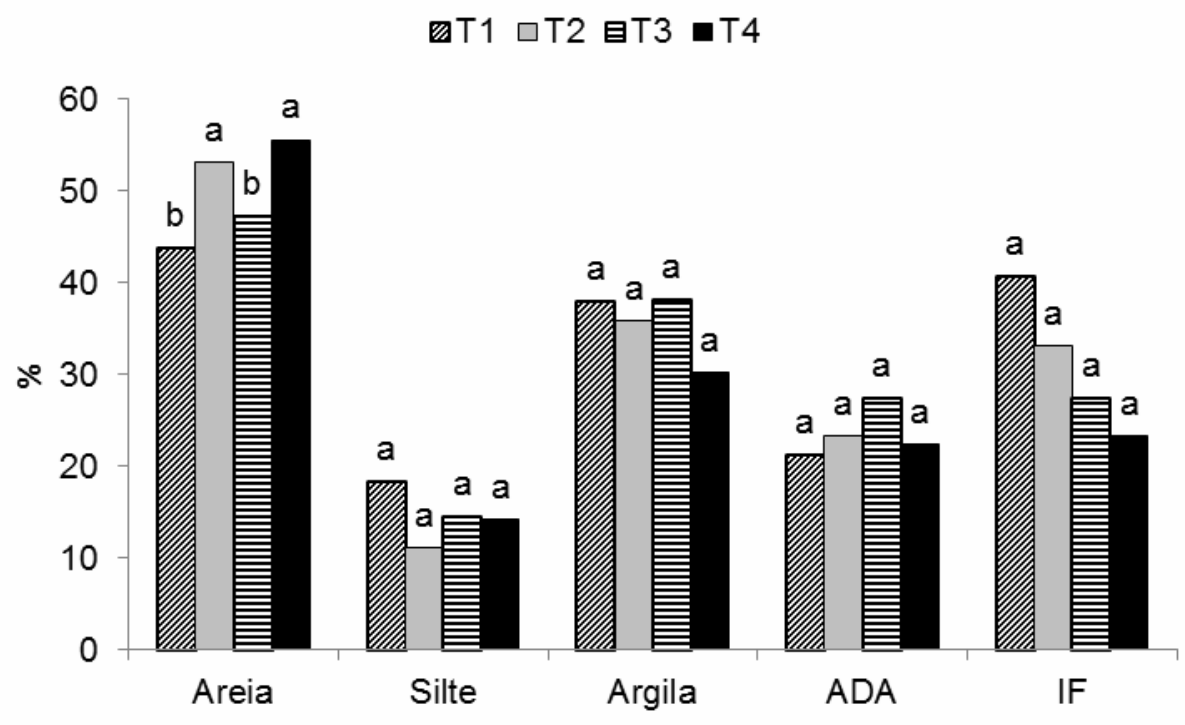

FIGURA 5 Atributos avaliados (areia, silte, argila, ADA e IF) na camada de 10-20 cm, para os tratamentos (T1: adubo verde recém roçado, T2: adubo verde há 1 ano, T3: adubo verde há 3 anos e T4: sem adubo verde). Médias iguais comparando os tratamentos para cada atributo avaliado não diferem entre si pelo teste de Scott-Knott à $5 \%$ de probabilidade.

\section{CONCLUSÕES}

A prática de adubação verde no município de Capim Branco - MG não tem sido contínua ao longo dos ciclos de cultivo, e, portanto não promoveu melhoria na qualidade do solo avaliado pela estabilidade de agregados.

\section{AGRADECIMENTOS}

À UFSJ, ao CVT Guayi, ao PET Agronomia e ao CNPq, pelos recursos disponibilizados para a execução do trabalho.

\section{REFERÊNCIAS}

ALCÂNTARA, F. A.; FURTINI NETO, A. E.; PAULA, M. B. et al. Adubação verde na recuperação da fertilidade de um latossolo vermelho-escuro degradado. Pesquisa Agropecuária Brasileira, v. 35, n. 2, p. 277-288, 2000.

ANDRADE, R. da S.; STONE, L. F.; SILVEIRA, P. M. da. et al. Culturas de cobertura e qualidade física de um Latossolo em plantio direto. Revista Brasileira de Engenharia Agrícola e Ambiental, v. 13, n. 4, p. 411-418, 2009.

BERTOL, I.; ALBUQUERQUE J. A.; LEITE, D.; AMARAL, A. J.; ZOLDAN JUNIOR, W. A. Propriedades físicas do solo sob preparo convencional e semeadura direta em rotação e sucessão de culturas, comparadas às do campo nativo. Viçosa. Revista Brasileira de Ciência do Solo, v. 28, n.1, p. 155 -163. 2004.

BETIOLI JÚNIOR, E.; MOREIRA, W. H.; TOTMENA, C. A.; FERREIRA, C. J. B.; SILVA, A. P.; GIAROLA, N. F. B. Intervalo hídrico ótimo e grau de compactação de 
um Latossolo Vermelho após 30 anos sob plantio direto. Revista Brasileira de Ciência do Solo, v. 36, p. 971-982, 2012.

BUZINARO, T. N.; BARBOSA, J. C.; NAHAS, E. Atividade microbiana do solo em pomar de laranja em resposta ao cultivo de adubos verdes. Revista Brasileira de Fruticultura, v. 31, n. 2, p. 408-415, 2009.

CALEGARI, A.; MONDARDO, A.; BULISANI, E. A.; COSTA, M. B. B.; MIYASAKA, S.; AMADO T. J. C. Aspectos gerais de adubação verde. In: COSTA, M. B. B. Adubação verde no sul do Brasil. 2. ed. Rio de Janeiro: ASPTA, p. 1-55.1993.

CARDOSO, D. P.; SILVA, M. L. N.; CARVALHO, G. J. de; FREITAS, D. A. F. de; AVANZI, J. C. Espécies de plantas de cobertura no recondicionamento químico e físico do solo. Revista Brasileira de Ciências Agrárias, v. 8, n. 3, p. 375-382, 2013.

CARVALHO, M. A. de; RUIZ, H. A.; COSTA, L. M. et al. Composição granulométrica, densidade e porosidade de agregados de Latossolo Vermelho sob duas coberturas do solo. Revista Brasileira de Engenharia Agrícola e Ambiental, v. 18, n. 10, p. 1010-1016, 2014.

CASTRO FILHO, C.; MUZILLI, O.; PODANOSCHI, A. L. Estabilidade dos agregados e sua relação com o teor de carbono orgânico num Latossolo Roxo distrófico, em função de sistemas de plantio, rotações de culturas e métodos de preparo das amostras. Revista Brasileira de Ciência do Solo, Campinas, v. 22, n. 3, p. 527538, 1998.

CUNHA, E. Q.; STONE, L. F.; MOREIRA, J. A. A.; FERREIRA, E. P. B.; DIDONET A. D.; LEANDRO, W. M. Sistemas de preparo do solo e culturas de cobertura na produção orgânica de feijão e milho. I - Atributos físicos do solo. Revista Brasileira de Ciência do Solo, v. 35, p. 589-602, 2011.

EMBRAPA. Manual de métodos de análise de solo. 2. ed. revista. Rio de Janeiro: Embrapa Solos, 2011. 230 p.

FERREIRA, M. M. Caracterização física do solo. In: LIER, Q. J. Física do solo. Viçosa: Sociedade Brasileira de Ciência do Solo, p.1-27. 2010.

FONTANÉTTI, A.; CARVALHO, G. J. de; GOMES, L. A. A. et al. Adubação verde na produção orgânica de alface americana e repolho. Horticultura Brasileira, v. 24, n. 2, p. 146-150, 2006.

HICKMANN, C.; COSTA, L. M. da. Estoque de carbono no solo e agregados em Argissolo sob diferentes manejos de longa duração. Revista Brasileira de Engenharia Agrícola e Ambiental, v. 16, n. 10, p. 1055-1061, 2012.

HICKMANN, C.; COSTA, L. M. da; SCHAEFER, C. E. G. R. et al. Morfologia e estabilidade de agregados superficiais de um argissolo vermelho-amarelo sob diferentes manejos de longa duração e mata atlântica secundária. Revista Brasileira de Ciência do Solo, v. 35, n. 6, p. 2191-2198, 2011. 
mapcoordinates.net. Disponível em: <http://www.mapcoordinates.net/pt>. Acesso em 11 de jun. 2015.

MIRANDA, M. A.; OLIVEIRA, E. E. M. de; SANTOS, K. C. F. et al. Condicionadores químicos e orgânicos na recuperação de solo salino-sódico em casa de vegetação. Revista Brasileira de Engenharia Agrícola e Ambiental, v. 15, n. 5, p. 484-490, 2011.

OLIVEIRA, D. M. S.; LIMA, R. P. de; JAN VERBURG, E. E. Qualidade física do solo sob diferentes sistemas de manejo e aplicação de dejeto líquido suíno. Revista Brasileira de Engenharia Agrícola e Ambiental, v. 19, n. 3, p. 280-285, 2015.

PERIN, A.; GUERRA, J. G. M.; TEIXEIRA, M. G.; PEREIRA, M. G.; FONTANA, A. Efeito da cobertura viva com leguminosas herbáceas perenes na agregação de um Argissolo. Revista Brasileira de Ciência do Solo, v. 26, n. 3, p. 713-720, 2002.

SILVA, E.; DE-POLLI, H.; GUERRA, J. G. M.; et al. Sucessão entre cultivos orgânicos de milho e couve consorciados com leguminosas em plantio direto. Horticultura Brasileira, v. 29, n. 1, p. 57-62, 2011.

SINGER, M.; EWING, S. Soil quality. In: SUMNER, M. E. (ed.). Handbook of soil science. Boca Raton: CRC Press, p.271-298. 2000.

STEFANOSKI, D. C.; SANTOS, G. G.; MARCHÃO, R. L. PETTER, F. A.; PACHECO, L. P. Uso e manejo do solo e seus impactos sobre a qualidade física. Revista Brasileira de Engenharia Agrícola e Ambiental, v. 17, n. 12, p. 1301-1309, 2013.

TUBALDINI, M.A.; COELHO, P.E. Formação de pólo de horticultura orgânica: a influência do trabalho familiar e assalariado e o meio ambiente. In: ENCONTRO DA ASSOCIAÇÃO BRASILEIRA DE ESTUDOS POPULACIONAIS. 13., 2002. Anais. Ouro Preto, 2002. CD-ROM

VASCONCELOS, R. F. B. de; SOUZA, E. R. de; CANTALICE, J. R. B. et al. Qualidade física de Latossolo Amarelo de tabuleiros costeiros em diferentes sistemas de manejo da cana-de-açúcar. Revista Brasileira de Engenharia Agrícola e Ambiental, v. 18, n. 4, p. 309-316, 2014. 